\title{
Organização da fala-em-interação: 0 dispositivo para 0 gerenciamento de fala sobreposta na conversa cotidiana em dados de português brasileiro
}

\section{The Overlap Management Device for Ordinary Conversation in Brazilian Portuguese Data}

Pedro de Moraes Garcez

Universidade Federal do Rio Grande do Sul (UFRGS), Porto Alegre, Rio Grande do Sul, Brasil.

pmgarcez@pq.cnpq.br

Fabíola Stein

Universidade Federal do Rio Grande do Sul (UFRGS), Porto Alegre, Rio Grande do Sul, Brasil.

fabiola_stein@hotmail.com

Resumo: Na fala-em-interação social, é comum que os participantes falem em sobreposição. Por vezes, isso se torna problemático para as suas ações, o que exige gerenciamento e resolução da fala sobreposta. Apresentam-se aqui os resultados de estudo sobre fala simultânea e o dispositivo para o seu gerenciamento em interações cotidianas em que a língua de interação é o português brasileiro. Com o intuito de verificar se a ocorrência do fenômeno e o funcionamento do dispositivo se dão conforme a descrição seminal feita por Schegloff(2000a), que tem como base dados de conversa entre falantes de inglês norte-americano, dois encontros entre três participantes conversando em português brasileiro foram gravados, transcritos e analisados sequencialmente sob a perspectiva teórico-metodológica da Análise da Conversa Etnometodológica (ACE). Após revisão, à luz da análise dos nossos dados, dos principais aspectos de ocorrência de fala sobreposta não problemática, bem como de fala 
sobreposta problemática e seu gerenciamento, conclui-se que a descrição de Schegloff (2000a) aplica-se aos dados de conversa em português brasileiro examinados.

Palavras-chave: Conversa; Fala-em-interação; Sobreposição; Interrupção; Tomada de turnos.

\begin{abstract}
Overlapping talk is a common occurrence in talk-ininteraction, even if at times participants may find it problematic while carrying out their actions, and will thus work to manage and resolve it. Results are reported here of an investigation of overlapping talk and the overlap management/resolution device component of turn-taking for ordinary conversation in Brazilian Portuguese. With the aim of verifying the adequacy of Schegloff's (2000a) description of such phenomena, which was based on conversation among speakers of American English, two encounters among three participants having conversations in Brazilian Portuguese were recorded, transcribed and analyzed following conversation analytic methods. We conclude that Schegloff's (2000a) description of overlapping talk and the overlap management/resolution device applies to our Brazilian Portuguese conversation data.
\end{abstract}

Keywords: Conversation; Talk-in-Interaction; Overlap; Interruption; TurnTaking.

Recebido em 18 de fevereiro de 2014. Aprovado em 03 de junho de 2014.

\title{
Introdução ${ }^{1}$
}

Quando as pessoas falam umas com as outras em interação, elas normalmente falam uma de cada vez e uma após a outra. Quando sua fala não é produzida serialmente

\footnotetext{
${ }^{1} \mathrm{O}$ trabalho de pesquisa relatado aqui foi realizado com apoio do CNPq mediante bolsas PQ (processos n 304311/2007-3 e n³06133/2010-5) e IC (PIBIC-Propesq/UFRGS).
} 
dessa maneira, elas geralmente agem rapidamente para restabelecer a "ordem"; alguém rapidamente preenche o silêncio; alguém para de falar (ou vários alguéns param) para resolver a fala simultânea; ou, se dois ou mais participantes continuam a falar, suas falas tomam um caráter especial de "competitividade". Esses estados especiais de silêncio ou competitividade, contudo, são rapidamente resolvidos em favor da "normalidade" do fala um de cada vez, nada mais, nada menos (SCHEGLOFF, 1987, p. 207). ${ }^{23}$

É pelo uso da linguagem na fala-em-interação que as pessoas conduzem grande parte de suas atividades conjuntas. Contudo, embora a linguagem humana em si tenha sido desde há milênios considerada passível de descrição por sua natureza evidentemente regrada, apenas nas últimas décadas alcançou-se um entendimento de que a fala-em-interação social é organizada sistematicamente e, portanto, também passível de descrição. De fato, "a organização das práticas para a tomada de turnos na fala-em-interação está entre aqueles elementos da vida social que, por estarem tão arraigados na prática do senso comum cotidiano, desafiam a consciência articulada e a descrição explícita, disciplinada" (SCHEGLOFF, 2000a, p. 2) ${ }^{4}$

A Análise da Conversa Etnometodológica (doravante ACE ver GARCEZ, 2008), perspectiva teórico-metodológica que orienta este trabalho, tem como meta principal "a descrição e explicação das competências que falantes quaisquer usam e das quais dependem ao

\footnotetext{
${ }^{2}$ As citações deste e demais trechos de obras sem publicação anterior conhecida em português aparecem aqui em nossa tradução para os fins deste trabalho. Os trechos na língua original seguem apresentados em notas.

3 "When persons talk to each other in interaction, they ordinarily talk one at a time and one after the other. When their talk is not produced serially in this manner, they generally act quickly to restore the 'order'; someone quickly steps in to fill the silence; someone stops talking (or several someones do) to resolve the simultaneous talk; or if two or more of the participants continue talking, their talk takes on a special character of 'competitiveness'. These special states of silence or competitiveness, however, are quickly resolved in favor of "normality' one at a time, no more, no less."

4 "The organization of turn-taking practices in talk-in-interaction is among those features of social life that are so deeply embedded in ordinary common-sense practice that they challenge articulate awareness and explicit, disciplined description."
} 
participar de interação inteligível socialmente organizada" ${ }_{5}$ (ATKINSON; HERITAGE, 1984, p. 1). Consiste, portanto, no estudo dos procedimentos empreendidos pelos participantes da interação para co-construírem suas ações sociais, "para produzir o próprio comportamento e para entender e lidar com o comportamento dos outros" (GARCEZ, 2008, p. 18). ${ }^{6}$ Sendo "a distribuição ordenada de oportunidades para participar de interações sociais uma das mais fundamentais pré-condições para a organização social viável"’ (SCHEGLOFF, 2000a, p. 1), o estudo da organização das práticas da tomada de turnos na fala-em-interação é também fundamental para quem estuda a ação humana pelo uso da linguagem em interação social.

Já Sacks, Schegloffe Jefferson (2003 [1974], doravante SSJ (2003 [1974])) apontavam que a sobreposição de vozes, isto é, mais de um participante produzindo atividade vocal ao mesmo tempo, é fenômeno recorrente na fala-em-interação, mesmo que a grande maioria das ocorrências seja breve e, conforme veremos, pouco ou nada problemáticas para a interação. Antes de SSJ (2003 [1974]), nos primórdios da tradição hoje conhecida como ACE, as lectures reunidas em Sacks (1992) já tratavam das bases sistemáticas para ocorrência de sobreposições, assim como Jefferson $(1973 ; 1983 ; 1984 ; 1986)$, que deu grande contribuição para os estudos do fenômeno da sobreposição de vozes na conversa. Nossa atenção aqui se volta, contudo, para o primeiro de dois artigos publicados no início da década passada sobre fenômenos relativos à fala sobreposta: Schegloff (2000a) e Schegloff (2002).

Schegloff (2000a) produziu uma nova e minuciosa descrição sobre o fenômeno da fala simultânea na conversa cotidiana, complementando e agregando grande precisão ao entendimento relatado em SSJ (2003 [1974]), sobretudo ao adicionar à sistemática da tomada de turnos mais um componente: ${ }^{8}$ o dispositivo para o gerenciamento de fala

\footnotetext{
${ }^{5}$ Tradução revisada de Garcez (2008, p. 18): "[...] the description and explication of the competence that ordinary speakers use and rely on in participating in intelligible, socially organized interaction".

6 "[...] produce their own behavior and understand and deal with the behavior of others". 7 "The orderly distribution of opportunities to participate in social interaction is one of the most fundamental preconditions for viable social organization."

${ }^{8}$ Os componentes descritos em SSJ (2003 [1974]) são: composição de turnos, que diz respeito às unidades com que o turno é construído, e alocação de turnos, referente às possibilidades de selecionar quem será o próximo falante.
} 
sobreposta. ${ }^{9}$ Além disso, esse trabalho adquire especial importância, já que a sobreposição de vozes seria 'a 'estrela social' da família da organização da tomada de turnos, aquela que desperta o interesse popular" (SCHEGLOFF, 1995, p. 40). ${ }^{10}$ Esse fenômeno vem sendo tratado em muitos trabalhos de maneira imprecisa e precipitada, atribuindo-se, como em Coates (1997), a grande presença de sobreposições à "conversa de mulheres" e o respeito ao "fala-um-de-cada-vez" à "conversa de homens".

Schegloff (2000a) descreve a ocorrência e gerenciamento de sobreposições. Schegloff (2002) propõe a distinção definitiva entre fala sobreposta e interrupção, ${ }^{11}$ pondo em xeque trabalhos como os de West

${ }^{9}$ Chamamos de "dispositivo" os conjuntos de práticas e recursos sistematicamente empreendidos que podem ser observados nas interações. Na literatura analítica da conversa, encontramos dispositivos de diversas espécies, como o da tomada de turnos ou de categorização de pertencimento (SCHEGLOFF, 2007a), esse último composto por uma coleção de categorias e suas regras de aplicação.

10 "[...] the "social star" of the turn-taking family, the one which excites wide popular interest."

${ }^{11}$ Segundo Schegloff (2002, p. 301), “'Interrupção’é, em primeira instância, um termo não especializado; um termo comum de descrição na atividade prática da fala cotidiana. Diferentemente de 'sobreposição', não é um termo forjado para fazer o trabalho de 'mera descrição', nem é bem forjado para servir como instrumento para a análise 'disciplinada'. É um termo de reclamação, e a sua invocação pode comumente servir para implementar a ação de reclamar. Dado que os termos 'sobreposição' e 'interrupção' fazem parte de domínios tão contrastantes, a equivocidade de 'interrupção' para fala sobreposta é equívoca para além das fontes de equivocidade já mencionadas. Além disso, para as várias dimensões de análise pelos participantes que podem informar as posições que eles assumem quanto ao tratamento de uma sobreposição como interrupção, há a questão prática da sua "reclamabilidade" para essas partes, naquele momento, com aquelas elocuções sobrepostas e assim por diante". ["Interruption" is in the first instance a vernacular term; a term of vernacular description in the practical activity of ordinary talk. Unlike "overlap", it is not designed to do the work of "mere description", nor is it well-designed to serve as a tool for "disciplined" analysis. It is a term of complaint, and its invocation can ordinarily serve to implement the action of complaining. Because the terms "overlap" and "interruption" are part of such contrastive domains, the equivocality of "interruption" to overlapping talk is equivocal over and above the sources of equivocality already mentioned. Furthermore, to the several dimensions of analysis by the parties that may inform the stance they take up to the treatment of an overlap as an interruption there is the practical matter of its "complainability" for those parties, at that moment, with those overlapping utterances, and so forth]. 
164 Revista de Estudos da Linguagem, Belo Horizonte, v.23, n.1, p. 159-194, 2015

e Zimmerman (2010 [1983]) e de West (1998), entre tantos outros que, por não atentarem em bases tão precisas como as que estão formuladas em Schegloff (2000a) para os elementos da organização da tomada de turnos acionados regularmente no gerenciamento de sobreposições problemáticas, tomaram ocorrências de sobreposição de vozes como interrupção (sobre isso, ver também DREW, 2009, p. 70). Esses trabalhos atribuíram indiscriminadamente o "desrespeito ao fala-um-de-cada-vez" a categorizações em esferas de poder, gênero, etnia, classe etc. Criticando esses estudos, o autor mantém, no conjunto, o "fala-um-de-cada-vez" como orientação básica da organização para a conversa, constituinte de todas as ações e categorias sociais construídas na fala-em-interação social. Aponta, portanto, que, nas relativamente raras ocasiões em que alguém interrompe um interlocutor, de fato questões de categorização de pertencimento estão em jogo, às vezes até mesmo na ausência de fala sobreposta propriamente, o que coloca a sobreposição de vozes como um fenômeno distinto. Com efeito, Drew (2009) propõe que se abandone por inteiro o emprego do termo "interrupção" "como categoria técnica na análise da interação" (p. 92).12

Todos esses estudos em ACE sobre a organização da tomada de turnos para a conversa têm como base dados de interação em inglês norte-americano. Assim, uma questão de potencial interesse é se essas descrições operariam também em dados de conversa em outras línguas de interação. Pesquisadores como Wong (2000), Sidnell (2001) e McCleary e Leite (2013), por exemplo, investigaram o funcionamento de aspectos da sistemática de tomada de turnos mediante o exame de dados de falaem-interação em outras línguas e comunidades que não as de falantes do inglês norte-americano. Nosso interesse aqui, portanto, é verificar, assim como, de certa maneira, fizeram Gardner e Mushin (2007) com dados de conversa em uma língua australiana aborígene, se a descrição em Schegloff (2000a) é suficientemente adequada para ocorrências do fenômeno na fala-em-interação em que a língua de interação é o português brasileiro. ${ }^{13}$ Também pretendemos com este trabalho ilustrar os principais aspectos do fenômeno, apresentando análises que se pretendem mais acessíveis ao leitor/pesquisador brasileiro do que as do

\footnotetext{
12 "[...] as a technical category in analyzing interaction".

${ }^{13}$ Marega e Jung (2011) examinam a sobreposição de falas em conversa cotidiana em português brasileiro com vistas ao exame geral do fenômeno, sem levar em conta a descrição de Schegloff (2000a; 2002).
} 
artigo original (SCHEGLOFF, 2000a), tanto pela síntese quanto pelo fato de apresentarmos análises de dados em português.

Para tanto, expomos primeiramente algumas questões relacionadas à relevância da língua de interação para a organização da fala-eminteração, nossos dados de análise e o lugar da fala sobreposta na organização da fala-em-interação. A seguir, procedemos a uma exposição dos pontos mais centrais da descrição seminal de Schegloff (2000a) à luz dos nossos dados e discutimos a operação do dispositivo de gerenciamento de sobreposições em uma ocorrência de fala sobreposta prolongada.

Entendemos que a verificação que empreendemos aqui é relevante para o conhecimento, sobretudo em língua portuguesa, acerca do fenômeno da sobreposição de vozes em si e do dispositivo para seu gerenciamento como elementos constituintes da organização da falaem-interação humana. Chamamos a atenção ainda para o fato de que a fala sobreposta tem sido muitas vezes tomada como indício de categorias analíticas de interesse dos pesquisadores, como gênero e poder, sobretudo quando equacionada com interrupção. Neste artigo, entretanto, examinamos tão somente a sobreposição de vozes e seu gerenciamento, seguindo Schegloff (2002) em tomar a sobreposição de vozes como fenômeno que pertence à ordem da organização elementar da fala-em-interação humana e que tem relação, mas é distinto da noção e da atividade interacional de "interrupção". ${ }^{14}$

\section{Língua de interação e organização da fala-em-interação}

Tendo em vista que "a estrutura linguística entra em cena na medida em que as características de uma determinada língua proporcionam recursos diferentes e restrições particulares ao modo como as práticas interacionais são implementadas" (ZIMMERMAN, 1999, p.

\footnotetext{
${ }^{14}$ Apesar de não enfocar essa distinção no que segue, acreditamos que a compreensão da sobreposição de vozes e seu gerenciamento na fala-em-interação é também relevante para uma compreensão apurada de ocorrências, bem menos frequentes, em que um participante da fala-em-interação efetivamente interrompe outro. Também acreditamos ser relevante um emprego mais cauteloso e em bases mais sólidas dessa noção como ferramenta analítica para tratar de temas relativos a categorias de pertencimento social, para além da organização da fala-em-interação em si, ou ainda mais interessantemente, quando fala sobreposta e pertencimento a categorias sociais estão em jogo concomitantemente para a realização de ações em um dado momento interacional.
} 
197), ${ }^{15}$ entendemos que os elementos linguísticos da estrutura gramatical de uma determinada língua de interação são importantes recursos em que os participantes se baseiam para projetar o desenho apropriado de seus turnos (SIDNELL, 2001; OCHS; SCHEGLOFF; THOMPSON, 1996, p. 34). Com efeito, SSJ (2003 [1974], p. 41-47) já apontavam que são de natureza sobretudo sintática as unidades de construção de turnos que estão na base da sistemática elementar para a troca de turnos na conversa. Ainda que recursos prosódicos tenham sido enfatizados, tal entendimento não se alterou substancialmente décadas mais tarde, quando vários analistas da conversa se debruçaram sobre a organização, dessa feita com base em dados de fala-em-interação em outras línguas além do inglês (OCHS; SCHEGLOFF; THOMPSON, 1996). Assim, dado que a sintaxe varia de uma língua natural humana para outra, é preciso assegurar-se de que os elementos da organização da fala-eminteração, descritos com base em dados de determinada língua, de fato se configuram do mesmo modo quando é outra a língua de interação, antes de podermos tomá-los como válidos universalmente, ou mesmo para esse domínio de linguagem natural específico. Em outras palavras, procuramos ter cautela ao examinar a adequação do entendimento atual acerca da fala sobreposta, analisando como ela ocorre na conversa entre brasileiros que interagem em português.

Schegloff (2000b) argumenta que há "um lugar sócio-interacional já moldado por uma série de estruturas de práticas que parecem transcender os limites culturais e linguísticos de forma relativamente robusta" (SCHEGLOFF, 2000b, p. 234). ${ }^{16}$ Assim, até haver prova em contrário, a organização da fala-em-interação seria estável através dos limites linguísticos e culturais e, ao mesmo tempo, adaptável a suas especificidades. Assim como fizeram Garcez e Loder (2005) com a descrição da organização de reparo, nosso objetivo, agora em relação às sobreposições de vozes, é averiguar se a descrição de Schegloff (2000a) se mostra ou não "estável através dos limites culturais e linguísticos"

15 "Linguistic structure enters in to the extent that the features of a given language provide differing resources and particular constraints on how interactional practices are implemented."

${ }^{16}$ Tradução de Garcez e Loder (2005, p. 281): “[...] a social-interaction site already shaped by a range of structures of practices which seem to transcend cultural and linguistic boundaries in a relatively robust way". 
entre participantes de fala-em-interação em inglês norte-americano e participantes de fala-em-interação em português brasileiro.

\section{Dados de análise}

A organização da tomada de turnos para a conversa cotidiana é o sistema elementar e fundador da fala-em-interação, a pedra fundamental da socialidade (SSJ, 2003 [1974], p. 55; ATKINSON; HERITAGE, 1984, p. 12; GARCEZ, 2008, p. 25-27). Consideramos a conversa "a forma básica de sistema de troca de fala, com outros sistemas na disposição representando uma gama de transformações do sistema de tomada de turnos da conversa, para se alcançarem outros tipos de sistemas" (SSJ, 2003 [1974], p. 55). Além disso, a conversa cotidiana em interação social face a face é o uso da linguagem presente em todas as sociedades humanas, não requerendo habilidade ou treinamento especial, além da própria socialização inicial em um grupo humano e constituindo o ambiente interacional em que se dá a própria aquisição da linguagem (CLARK, 2000 [1996]).

Podemos encontrar, portanto, diferentes sistemas de troca de falas em atividades institucionais como uma aula, palestra ou conferência, uma consulta médica, uma audiência ou julgamento - com diferentes organizações de tomada de turnos. Esses diferentes sistemas parecem ser "produto de transformações ou modificações do sistema da conversa cotidiana, que é a organização primordial da fala-em-interação" "17 (SCHEGLOFF, 1987, p. 222), constituindo-se como institucionais pelas modificações observáveis em alguns aspectos que organizam a conversa cotidiana (GARCEZ, 2002), especialmente no que diz respeito às sistemáticas centrais para a conversa, nomeadamente, tomada de turnos e reparo.

Devido à primordialidade da conversa sobre os diversos sistemas de troca de fala, fazer primeiramente uma descrição sistemática de um componente da tomada de turnos, como o dispositivo de gerenciamento de sobreposições, com dados de conversa cotidiana, parece-nos necessário. Schegloff (2000a) faz isso com dados de conversa em inglês norte-americano. Assim, para verificar a propriedade dessa descrição em relação a sua operação em uma outra língua de interação, o português brasileiro, precisamos ter como base o mesmo sistema de troca de fala,

17 " [...] product of transformations or modifications of the one for conversation, which is the primordial organization for talk-in-interaction." 
a conversa cotidiana. Para isso, tendo obtido o consentimento informado dos participantes, fizemos o registro audiovisual de duas conversas cotidianas, totalizando cerca de uma hora e meia de gravação. Em ambos os casos, são grupos de amigos, três jovens do mesmo sexo e com níveis de escolaridade semelhantes, que estão sentados, na sala de estar de um deles, antes de uma refeição. Segmentamos os dados, atentos à ocorrência de sobreposições, encontrando diversas ocorrências do fenômeno, o que gerou, assim, dados para examinar boa parte dos aspectos mais elementares descritos em Schegloff (2000a). Utilizamos pseudônimos para preservar as identidades dos participantes cujas produções aparecem nos segmentos transcritos, segundo as convenções Jefferson (ver LODER, 2008). Além disso, o registro da conversa também em vídeo nos permite, como aos participantes, explorar o caráter multimodal da interação.

\section{Organização da fala-em-interação e sobreposições de vozes}

Conforme já mencionado, em Sacks, Schegloffe Jefferson (2003 [1974]) temos a descrição seminal da sistemática para a organização da tomada de turnos para a conversa. Essa sistemática funciona como um dispositivo organizacional que permite às partes da conversa "a conquista da arquitetada característica de uma-parte-por-vez, mesmo em face de uma mudança recorrente quanto a quem seria a parte a falar, e ainda assim prevendo ocasiões de multiplicidade de falantes e lapsos na fala (isto é, silêncios) que as partes podem empreender em conjunto"18 (SCHEGLOFF, 2000a, p. 2). A organização da conversa se baseia em um conjunto de orientações normativas que governam a própria construção do turno e são responsáveis pela "alocação de um turno seguinte a uma parte [...] [e] que coordenam a transferência, de modo a minimizar intervalos e sobreposições" (SSJ, 2003 [1974], p.16, grifo nosso), afastamentos da orientação básica da conversa, "fala-um-de-cada-vez".

Schegloff (2000a) descreve um componente da organização da tomada de turnos que não havia sido tratado em SSJ (2003 [1974]): o dispositivo para o gerenciamento de fala sobreposta. A renovada

\footnotetext{
18 "An organizational device that would allow parties to achieve the design feature of one-party-at-a-time in the face of a recurrent change in who the speaking party was, while providing as well for such occasions of multiple speakership and lapses in the talk (i.e. silence) as the parties might undertake to co-construct."
} 
atenção analítica do autor para tal componente levou à articulação precisa de aspectos da sistemática da tomada de turnos para a conversa que em SSJ (2003 [1974]) eram apenas mencionados. Assim, ao analisar se ocorrências de sobreposições de vozes são tratadas pelos participantes como problemáticas ou não, que recursos eles mobilizam para o gerenciamento e resolução, quando e como, Schegloff (2000a) explicita o que vem a ser "breve" quando SSJ (2003 [1974]) afirmam que "ocorrências de mais de um falante de cada vez são comuns, mas breves" (SSJ, 2003 [1974], p. 19). Disso resulta uma compreensão bastante apurada de como apenas uma parcela muito pequena dessas sobreposições compromete o andamento da interação, conforme os dados de Schegloff (2000a) e os nossos demonstram.

\section{Sobreposições de vozes}

Quando dois participantes se encontram falando em sobreposição, depois da primeira batida rítmica de fala simultânea,${ }^{19}$ cada parte precisa tomar posição quanto à sobreposição em desenvolvimento, podendo "desistir", parar de falar; continuar como se não houvesse outra pessoa falando; ou promover a produção da competição pela mobilização de um ou mais recursos para o gerenciamento da sobreposição (SCHEGLOFF, 2002, p. 292). Nesse ponto, cada parte pode considerar a posição tomada pelo coparticipante e reagir frente a isso. Observamos que nisso se coloca como relevante um outro nível de granularidade, ${ }^{20}$ pois a orientação não é somente para o "turno a turno" e sim para a "batida a batida", isto é, para a decisão que cada parte toma a cada nova batida de fala sobreposta.

Tendo em vista essas diferentes posições que os participantes podem tomar frente à sobreposição de vozes, podemos pensar em ocorrências que não tomam um caráter de competitividade, com um participante parando de falar e outro continuando, e ocasiões em que uma ou as duas partes mobilizam recursos, como aumento de volume ou

\footnotetext{
${ }^{19}$ Conforme Schegloff (2000a, p.19; ver também nota 22 de SCHEGLOFF, 2000a, p. 51-52), o que constitui uma batida rítmica ainda não está totalmente entendido. No entanto, pensar na correspondência entre batida e sílaba não está de todo equivocado. ${ }^{20}$ A noção de granularidade tem a ver com a magnitude ou escopo do que os participantes formulam ou demonstradamente notam, como no caso do gerenciamento de sobreposições (SCHEGLOFF, 2000c).
} 
velocidade da fala, para gerenciar a sobreposição e assim resolvê-la, ou seja, colocando em funcionamento o dispositivo para o gerenciamento de fala sobreposta. Temos, então, dois tipos de sobreposições de vozes: sobreposições não problemáticas e sobreposições problemáticas (para o andamento da interação).

Observemos a seguir, mais detidamente, cada tipo de sobreposição. Primeiro, examinaremos algumas ocorrências de sobreposições não problemáticas que, já em um primeiro momento, podemos excluir do domínio da operação do dispositivo para o gerenciamento de fala sobreposta. Em seguida, examinaremos dados de sobreposições problemáticas, em que observamos o empreendimento de recursos para o gerenciamento da sobreposição.

\subsection{Sobreposições não problemáticas}

Há ocorrências de sobreposição tratadas como não problemáticas na conversa que não precisam de práticas especiais para seu gerenciamento, isto é, os falantes em sobreposição não parecem estar competindo pelo turno, nem demonstram que a ocorrência de sobreposição é obstáculo às suas ações. Nesses casos, "a conduta dos participantes não demonstra que essas ocorrências são tomadas como problemáticas para eles, e é essa característica que rege o tratamento que damos a elas como analistas"21 (SCHEGLOFF, 2000a, p. 4). Privilegiamos, portanto, a perspectiva dos interagentes, pois "parece sustentado empiricamente o fato de que os participantes precisam demonstrar entendimento do que foi dito e feito ao agirem aqui e agora" (GARCEZ, 2008, p. 28). É sobre esse procedimento de articulação da análise dos participantes que tomamos uma sobreposição como problemática ou não.

É importante destacar que consideramos a fala sobreposta como fenômeno que requer atenção organizacional dos participantes somente quando as vozes sobrepostas se encontram em uma única conversa, isto é, quando há falas sobrepostas de falantes que são participantes da mesma conversa. Nos casos de conversas distintas, porém espacialmente próximas, não temos sobreposições de vozes nos termos organizacionais que nos interessa

21 " [...] the conduct of the participants does not show these occurrences to be taken as problematic by them, and this feature governs their treatment by us as analysts." 
aqui compreender e descrever, pois a orientação dos participantes para o "falaum-de-cada-vez" se restringe ao universo do encontro em cada conversa. ${ }^{22}$

Mesmo em sobreposições de vozes em uma mesma conversa, contudo, há quatro tipos de ocorrências em que, em uma primeira instância, a sobreposição de voz não é problemática em relação à tomada de turnos, ou seja, não é um obstáculo interacional para o que os participantes estão fazendo (SCHEGLOFF, 2000a, p. 4-7):

a. Sobreposições terminais - ocorrem quando um falante inicia sua fala antes que o outro acabe, por projetar precocemente o término do turno do interlocutor. Nesse caso, a sobreposição acaba uma batida após o começo, autoliquidando-se;

Excerto (1): Sobreposição terminal ${ }^{23}$

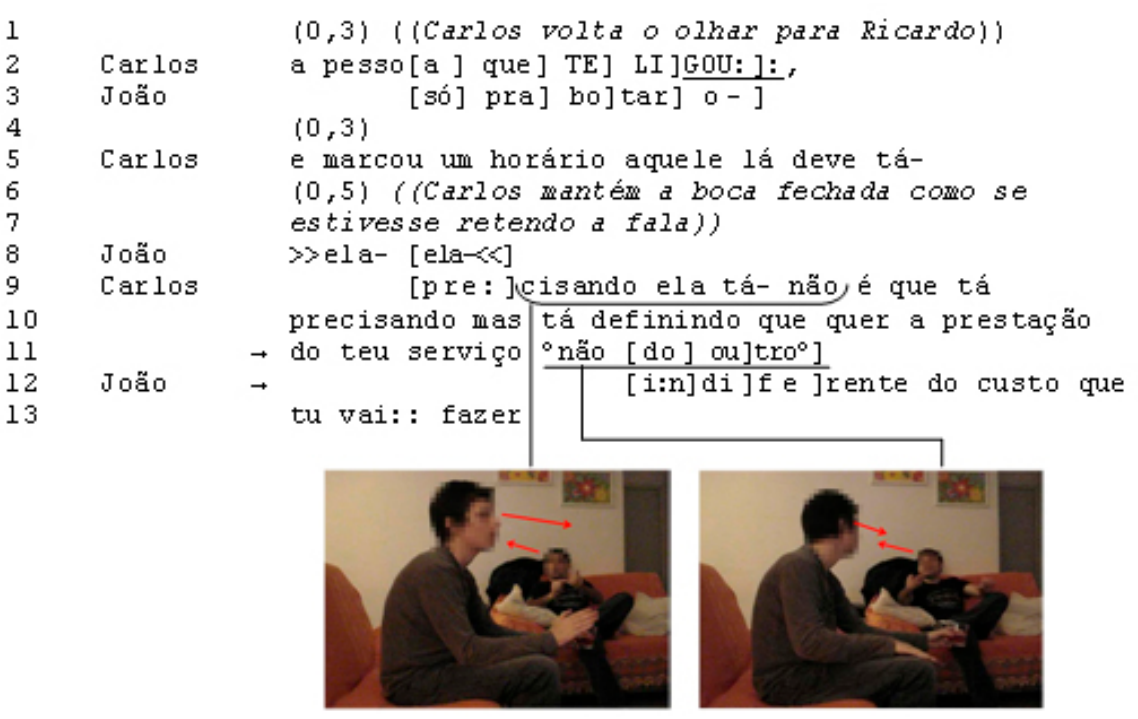

${ }^{22}$ É também comum em conversas com quatro ou mais participantes ocorrerem momentos de cisma, ou seja, o que era uma conversa com quatro participantes, por exemplo, se torna duas conversas com dois participantes cada uma. É importante estar atento a isso em transcrições e análises de dados, separando as duas conversas para que não se busquem relações sequenciais entre duas conversas distintas.

${ }^{23}$ As convenções utilizadas para transcrição de todos os excertos reproduzidos neste trabalho encontram-se no apêndice. 
Nesse dado, encontramos três ocorrências de sobreposição de vozes: linhas 2 e 3; linhas 8 e 9; e linhas 11 e 12. Nessa conversa, três amigos, Carlos, João e Ricardo, estão discutindo prestação de serviços de informática e de estética. Carlos, que é cabeleireiro, está nesse momento argumentando sobre a relação entre a qualidade do serviço e a cobrança feita. João entra em sobreposição à fala de Carlos em três momentos para contribuir com a argumentação do amigo. A sobreposição que nos interessa examinar agora é a terceira. Carlos, na linha 11, poderia terminar seu turno em "do teu serviço", onde já encontramos uma unidade de construção de turno completa. Contudo, Carlos ainda produz um adendo a essa produção em volume de voz mais baixo, "não do outro", voltando o olhar para João. Na linha 12, João, já tendo anteriormente tentado contribuir com a argumentação de Carlos, trata "do teu serviço" como o final do turno do interlocutor. Ao produzir "não do outro", Carlos não apresenta quaisquer perturbações na sua elocução e direciona o olhar para João. Assim, essa ocorrência de sobreposição não é considerada como problemática pelas partes, pois se configura apenas como uma projeção precoce de João do término do turno de Carlos que, mesmo durando mais de uma batida, possui a ratificação de Carlos, que nesse momento volta o olhar para João, como se "concedesse" o turno.

São comuns as sobreposições que ocorrem pela projeção precoce do término da fala do interlocutor que se autoliquidam, pois o interlocutor logo completa seu turno sem reclamar pelo espaço de turno, sem competir pela vez de falar.

b. Continuadores - demonstrações de atenção do interlocutor para a fala em andamento;

\section{Excerto (2): Continuadores}

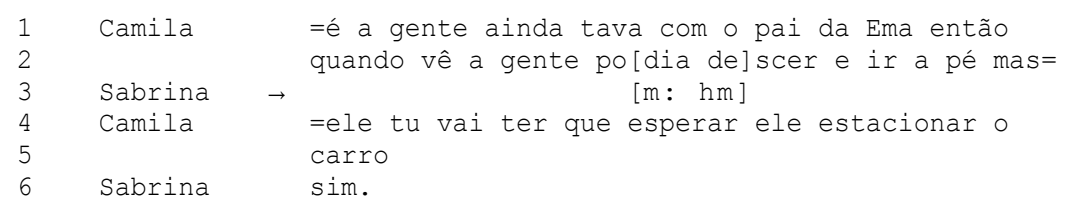

Outro caso de sobreposição não problemática pode ser visto nas linhas 2 e 3, em que Sabrina entra em sobreposição ao turno de Camila, demonstrando atenção ao que a amiga está dizendo. Camila está tentando 
convencer Sabrina sobre a impossibilidade de chegar a tempo para um grande show de circo devido ao trânsito. Para isso, ela faz o relato de quando foi a esse show em outra oportunidade. Assim, Camila, durante os momentos de relato, dá demonstrações de entendimento, como se estivesse acompanhando o ponto que a amiga está defendendo para convencê-la. Podemos ver que esse tipo de sobreposição não requer nenhum tipo de prática especial para o seu gerenciamento.

c. Acesso condicional ao turno - casos de busca de palavras e construção colaborativa de um turno;

Excerto (3): Acesso condicional ao turno

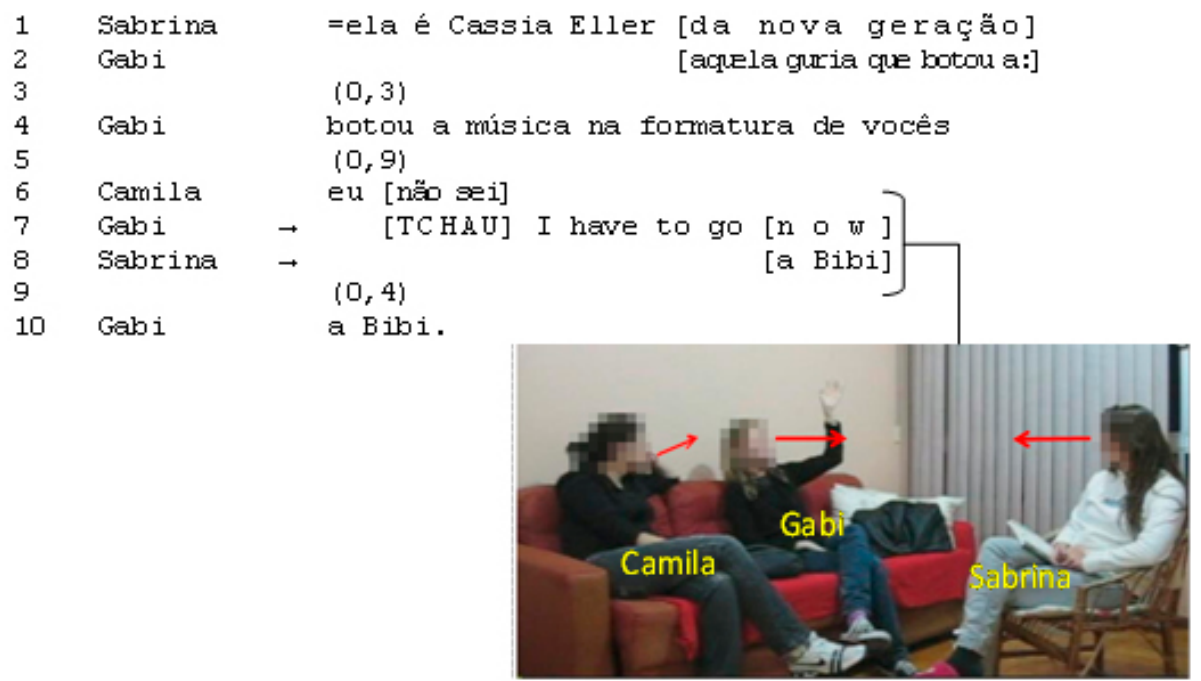

Falando sobre músicas para receber o diploma em formaturas, Gabi, na linha 7, faz um adendo à sua iniciação de reparo, começa a cantar a música que "uma guria colocou na formatura", olhando para Sabrina (conforme está indicado no quadro de imagem), para que a amiga saiba de quem ela está falando e, assim, possa ajudá-la na busca de palavra. Sabrina, logo ao ouvir a música, lembra-se do nome e fala em sobreposição (linha 8), olhando para Gabi e oferecendo o nome, que Gabi, na linha 10, confirma. Como Gabi estava construindo aquele turno para que Sabrina a ajudasse a lembrar o nome de alguém, uma vez oferecido o item, a amostra da música já fora suficiente antes do fim da frase da 
canção (e do turno). Logo, ao entrar em sobreposição, auxiliando na busca de palavra ao responder à pergunta, Sabrina não estaria competindo pelo turno e sim levando a cabo o reparo, respondendo às expectativas da interlocutora, e isso não precisaria ser feito necessariamente após a completude da frase (da música) no turno de adendo da iniciação de reparo para busca de palavra. De fato, Schegloff (2000a, p. 5-6) aponta sequências de reparo autoiniciado e levado a cabo pelo outro em busca de palavras e a construção de elocuções colaborativas como as duas instâncias mais familiares de ocorrências de sobreposições não problemáticas desse tipo.

d. Vozes em coro - risos, saudações coletivas, despedidas, parabenizações, cantorias etc. Atividades que são tratadas pelos participantes como produções a ser feitas deliberadamente em simultaneidade;

Excerto (4) (continuação do excerto (3)): Vozes em coro

\begin{tabular}{|c|c|c|c|}
\hline Gabi & & $\begin{array}{l}\text { [[foi essa música] o tempo inteiro.= } \\
{[[(\text { era agora, })]}\end{array}$ & \\
\hline Gabi & $\rightarrow$ & =tchau. [I have to go now. [I have to go now. & tcha: $u]=$ \\
\hline Sabrina & $\rightarrow$ & [ I have to go now. [ I have to go now. $(0,3)$ & $\overline{\text { tcha: } u]=}$ \\
\hline Camila & $\rightarrow$ & [I have to go now. $(0,3)$ & tcha: $u]=$ \\
\hline Gabi & & $=\left[\left[{ }^{(e)}\right.\right.$ ficou todo ${ }^{\circ} \circ$ tempo $\left(\right.$ assim $\left.^{\circ}{ }^{\prime}\right]$ & \\
\hline Sabrina & & $=\left[\right.$ [eu só queria ficar $\left[\mathrm{n} \tilde{a}\right.$ nã $\left.{ }^{\circ} \mathrm{na} i \mathrm{a}^{\circ}\right]$ & \\
\hline Cami & & {$[>$ de quem é essa música<] } & \\
\hline
\end{tabular}

Esse excerto, que é uma continuação do anterior, apresenta vozes em coro em uma atividade que parece ser tratada pelas participantes como propositalmente a ser feita em produções simultâneas, um coro de uma música. Gabi, na linha 13, não mais procurando uma palavra, mas apenas cantando a música para reforçar seu incômodo com ela, "convida" Sabrina e Camila para essa atividade. As duas participantes, uma após a outra, engajam-se na cantoria. Conforme previsto, não observamos gerenciamento de sobreposições.

\subsection{Sobreposições de vozes problemáticas}

No curso particular da ação em um dado momento da fala-eminteração, a tomada de turnos em sobreposição pode ser um obstáculo para 
os participantes. Se for mesmo assim, a sobreposição se caracteriza como um conflito ou obstáculo para o que está sendo feito. Nesse momento, então, as partes recorrem a um dispositivo para o gerenciamento de sobreposições a fim de dar prosseguimento à ação obstaculizada pelo desencadeamento das falas sobrepostas.

A seguir, temos a transcrição de um dado exemplar desse fenômeno. Nessa interação, temos três participantes, Carlos, João e Ricardo, conversando sobre negócios relacionados ao ramo de serviços de informática (nos quadros de imagem estão designados somente Carlos e João, pois Ricardo se encontra fora da área de captura da câmera de vídeo). No momento, Carlos está explicando a localização da $L A N$ house de um conhecido, e João entra em sobreposição para fazer uma pergunta relacionada à localização do estabelecimento.

Excerto (5): Sobreposição de vozes problemática

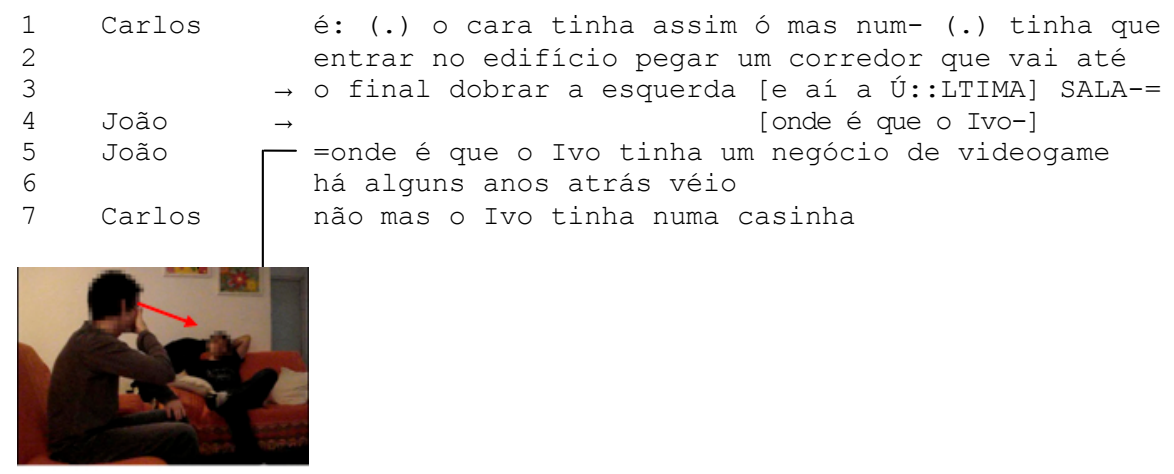

Carlos, logo após o início da fala simultânea de João, aumenta o volume de sua fala e prolonga um som, "ÚL::TIMA SALA-", cortando abruptamente sua fala em "SALA-" e direcionando seu olhar para João com a mão na boca, como pode ser visto no quadro de imagem. Diferentemente dos quatro casos apresentados na seção anterior ou de casos em que temos alguém desistindo de falar logo após a primeira batida de fala simultânea, podemos ver que nesse dado há o empreendimento de práticas para resolver a sobreposição. $\mathrm{O}$ dispositivo para o gerenciamento de sobreposições é acionado pelo emprego, orientado às batidas de fala simultânea, de determinadas práticas em determinados lugares. Assim, o gerenciamento da sobreposição não ocorre de maneira aleatória. Sobre isso nos deteremos a seguir. 


\section{0 dispositivo para o gerenciamento de fala sobreposta}

Tendo em vista que há sobreposições problemáticas e não problemáticas para a interação e que aquelas que se constituem como problemáticas, isto é, aquelas em que os participantes competem pelo turno, deflagram o acionamento de um dispositivo para o seu gerenciamento, vejamos no que se constitui esse dispositivo. Conforme foi descrito por Schegloff (2000a, p. 11), o dispositivo para o gerenciamento de sobreposições é composto por:

a. um conjunto de recursos de produção de turno;

b. um conjunto de lugares onde tais recursos são mobilizados;

c. uma "lógica" interacional em que tais recursos, em tais lugares, constituem "jogos" de uma espécie que pode ser descrita em uma topografia sequencial.

\subsection{Conjunto de recursos de produção de turno}

Os recursos empreendidos pelos participantes para o gerenciamento da sobreposição dividem-se nos chamados contratempos e perturbações. ${ }^{24}$ Os contratempos estão ligados à progressividade da fala em curso; por exemplo, cortes da fala em curso, prolongamento de um segmento da fala e repetição de algum elemento prévio. Já as perturbações estão ligadas a afastamentos do caráter prosódico da fala que está sendo articulada naquele ponto, ${ }^{25}$ como aumento de volume e aumento ou diminuição da velocidade.

\footnotetext{
${ }^{24}$ Nossa tradução para hitches e perturbations.

${ }^{25}$ Couper-Kuhlen e Selting (1996) afirmam "que a prosódia pode ser vista como um dos 'detalhes' ordenados da interação, um recurso do qual os interlocutores se valem para realizar a ação social e um meio para conduzir processos inferenciais" (COUPERKUHLEN; SELTING, 1996, p. 25). Além disso, sugerem que os recursos prosódicos funcionariam como dispositivos dos participantes, projetados para a organização e o gerenciamento da fala-em-interação, operando como "parte de um sistema de sinalização que - juntamente com a sintaxe, a léxico-semântica, a cinestesia e outras pistas de contextualização - é usado para construir e interpretar unidades de construção de turno e turnos de fala" (COUPER-KUHLEN; SELTING, 1996, p. 25). Em relação ao dispositivo para o gerenciamento de sobreposição, os recursos prosódicos se constituem como recursos de produção de turno. "[...prosody can be seen as one of the orderly 'details' of interaction, a resource which interlocutors rely on to accomplish social action and as a means of steering inferential processes [...] part of a signalling system
} 
Esses recursos, empreendidos na produção do turno em sobreposição, evidenciam que aquela fala simultânea está sendo tratada pelos participantes como um obstáculo interacional. Ao empregar esses recursos, portanto, os participantes sinalizam que estão competindo pela vez de falar, ou seja, há um esforço, por pelo menos uma das partes, para chegar a produções de fala em modo solo dos turnos sobrepostos.

Registre-se, contudo, que esses recursos só se constituem como tais por estarem estrategicamente posicionados. Uma hesitação, por exemplo, pode ser prática constituinte de uma ação despreferida (POMERANTZ, 1984; BILMES, 1988), ${ }^{26}$ como na rejeição a um convite. Nesse caso, essa prática (de hesitar) não se constituiu como um recurso para o gerenciamento de uma sobreposição, e sim como um constituinte da ação despreferida. Assim, as práticas de que os participantes lançam mão para gerenciar a sobreposição são recursos que estão a serviço da organização da tomada de turnos.

\subsection{Conjunto de lugares onde tais recursos são mobilizados}

As partes de uma conversa parecem se orientar para a trajetória temporal da sobreposição, identificando-se fases: pré-início, pós-início, pré-resolução e pós-resolução. Isso é relevante, pois o modo como uma prática é empregada (por exemplo, velocidade da fala em aceleração/

\footnotetext{
which - together with syntax, lexico-semantics, kinesics and other contextualization cues - is used to construct and interpret turn-constructional units and turns-at-talk."] 26 "É o trabalho interacional maior que certas ações acarretam o que evidencia a orientação dos participantes para o seu caráter de ações despreferidas" (LODER; SALIMEN; MULLER, 2008, p. 51). Pomerantz (2008) sustenta que "o modo como uma ação é executada permite que os outros infiram a perspectiva do ator quanto ao caráter de tal ação como desejável ou indesejável. A realização de uma ação de caráter preferido permite aos participantes inferir que o ator tem gosto em executar a ação. A realização de uma ação de caráter despreferido permite aos participantes inferir que o ator está hesitante e que vê a ação como indesejável e/ou desagradável" (POMERANTZ, 2008, p. 9). ["The way in which an action is performed allows others to infer the actor's stance regarding the status of action as desirable or undesirable. Preferred status enactment of an action allows participants to infer that the actor is enthusiastic about performing the action. Dispreferred status enactment allows participants to infer that the actor is hesitant and regards the action as undesirable and/or unpleasant."]
} 
desaceleração) difere conforme a fase da sobreposição.

a. Pré-início - recursos mobilizados antes do começo efetivo da sobreposição, por uma projeção de que o outro está para iniciar um turno.

Excerto (6) (já reproduzido antes como excerto (1)): Pré-início

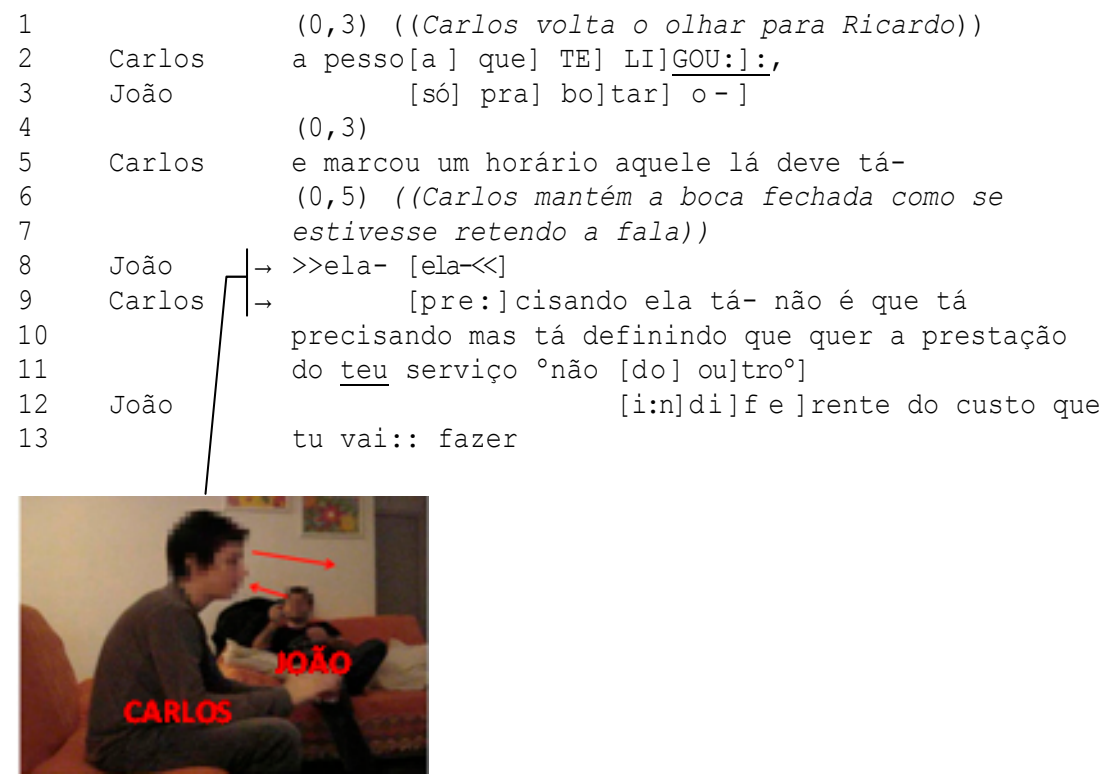

Reproduzimos novamente esse excerto, agora focando os turnos de João e Carlos nas linhas 8 e 9. Carlos corta sua fala na linha 4, talvez procurando por uma palavra. João toma o turno, com perturbações, aceleração e cortes, em antecipação à retomada de produção do turno por Carlos, que, nos 0,5 segundos de silêncio e enquanto João produz " $>>$ ela- ela-<<", mantém a boca fechada como se estivesse retendo a fala, direciona o olhar para Ricardo e segue gesticulando com a mão. Assim, o emprego dessas práticas específicas, antes do efetivo início da sobreposição, ${ }^{27}$ não é aleatório, mas uma tentativa de "não deixar

\footnotetext{
${ }^{27}$ McCleary e Leite (2013, p. 132-136) analisam ocorrência semelhante em dados de conversa em Libras, o que envolve grande desafio analítico, uma vez que, por se tratar
} 
espaço em que outro participante possa começar"28 (SCHEGLOFF, 2000a, p. 16).

A projeção de que o outro está para iniciar um turno é feita pelo comportamento corporal do interlocutor, como vimos nos dados anteriormente apresentados, ou por práticas pré-início de turno, como, por exemplo, inspirações audíveis antes do turno. Estamos então tratando de uma fase da sobreposição de vozes, em que, na verdade, não há vozes sobrepostas. O que ocorre é que "um tal falante que já está a falar pode valer-se de práticas que de resto estão disponíveis para lidar com fala sobreposta para tratar da expectativa de fala sobreposta incipiente e possivelmente impedi-la, nessa fase de pré-início" (SCHEGLOFF, 2000a, p. 15). ${ }^{29}$

b. Pós-início - recursos mobilizados logo após o começo da sobreposição.

\section{Excerto (7) (já reproduzido antes como excerto (5)): Pós-início}

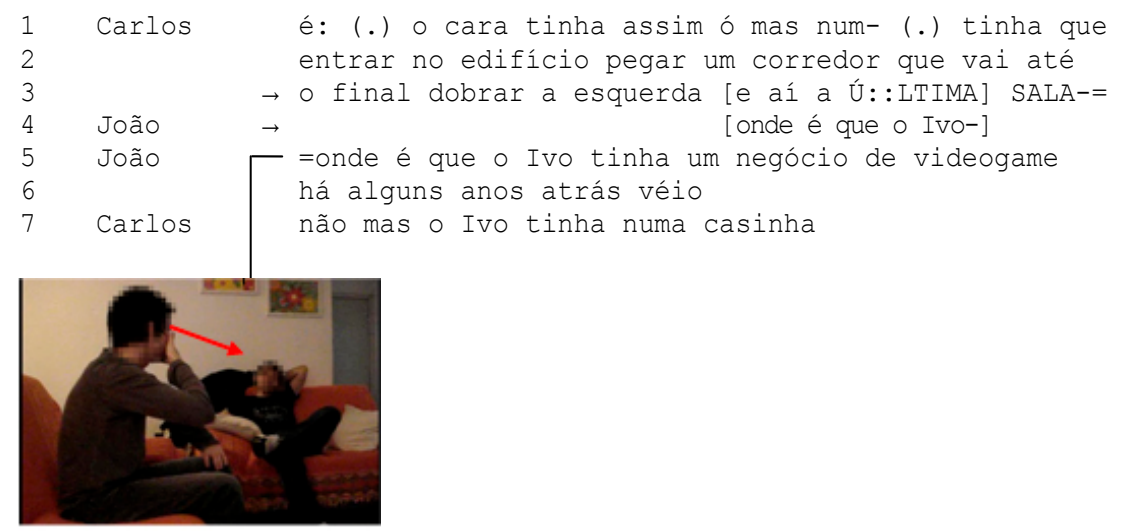

Conforme já analisamos anteriormente, ocorre aqui o gerenciamento de sobreposição de Carlos e João. Na linha 3, enquanto

de dados em uma língua de interação de modalidade espaço-visual, é difícil distinguir as práticas de pré-início.

28 "[...] as if to leave no room in which a new speaker could begin."

29 "Such an already-speaking speaker may deploy the practices otherwise available for dealing with overlapping talk to address the prospect of incipiently overlapping talk, and possibly to interdict it, in this 'pre-onset' phase." 
Carlos faz a descrição de como chegar até um estabelecimento comercial, João começa a falar em sobreposição (linha 4). Carlos, então, logo após o início dessa sobreposição, aumenta o volume da voz e alonga a vogal em "Ú::LTIMA SALA". O empreendimento dessas práticas, logo após o início da sobreposição, registra a resposta de uma ou das duas partes em sobreposição para o fato de que há outro falando ao mesmo tempo. Carlos compete pela vez de falar, o que tem efeito, pois João, após o início da produção competitiva, corta sua fala, deixando Carlos terminar o turno.

c. Pré-resolução - contratempos e perturbações mobilizados pouco antes da completude possível do turno.

Excerto (8): Pré-resolução

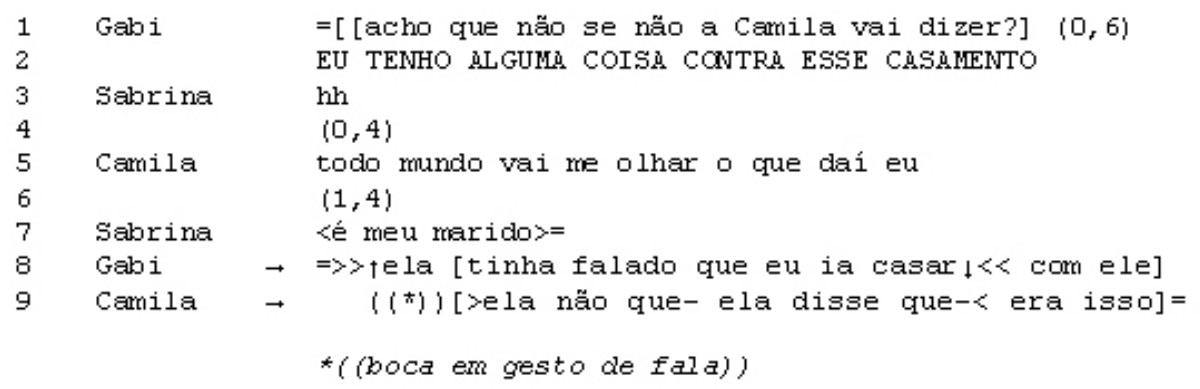

Adiante, analisaremos mais detalhadamente esse dado, em que vemos as três amigas em enquadre de brincadeira, encenando o que poderia ser dito no momento do casamento em resposta à pergunta “Alguém tem alguma coisa contra esse casamento?". Aqui vemos o empreendimento de práticas em posição de pré-resolução pela participante Camila. Podemos ver que, enquanto Gabi e Camila se aproximam da completude possível das unidades de construção de turno produzidas em sobreposição (linhas 8 e 9), cada uma pode escutar que a outra está chegando a uma completude possível. Assim, podemos observar Camila mobilizando recursos pouco antes da completude possível do turno de Gabi, em uma posição de pré-resolução da sobreposição, antes que a sobreposição efetivamente termine. Dessa maneira, Camila mantém sua fala até Gabi terminar o turno para poder realizar a contribuição no claro, isto é, sem sobreposição. Cortes e repetições seriam frequentes nessa fase por "manterem" o turno de quem busca continuar a falar logo em seguida 
à resolução da sobreposição.

d. Pós-resolução - ajustes da fala ao ambiente sem sobreposição após a fala emergir no claro, não havendo mais sobreposição.

Excerto (9) (já reproduzido antes como excertos (1) e (6)): Pósresolução

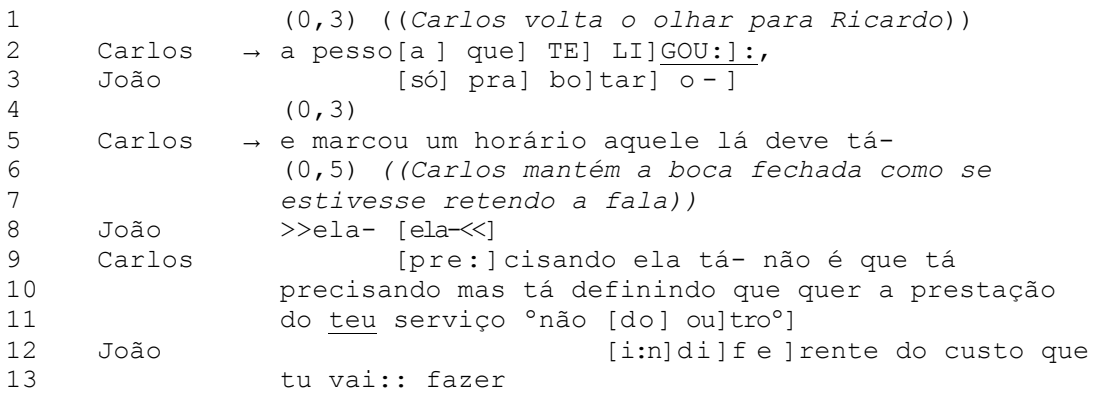

Olhando agora para as sobreposições que ocorrem nas linhas 2 e 3 , vemos algo semelhante ao que ocorre no excerto $(5) /(7)$, em que há o empreendimento de práticas para resolução da sobreposição, aumento de volume e alongamento de vogal, em uma posição de pós-início. Logo após Carlos iniciar sua produção competitivamente, em corte abrupto, João desiste do turno. Após um pequeno silêncio (linha 4), Carlos continua a frase, mas agora em volume normal, sem alongar vogais ou enfatizar sílabas. Numa fase de pós-resolução da sobreposição, linha 5, é necessário ajustar a fala para o ambiente sem sobreposição. Em nosso dado, imediatamente após a sobreposição se resolver, já não há mais perturbações na fala. Também é possível encontrar casos, como mostra Schegloff(2000a), em que o empreendimento das práticas persiste mesmo após a resolução da sobreposição, ou seja, o ajuste para o volume ou velocidade normal de fala se estende pelo turno seguinte feito no claro. $\mathrm{O}$ importante dessa fase de pós-resolução é que, se o ajuste não ocorresse, a produção de Carlos em volume mais alto poderia ser ouvida como raiva ou reclamação (SCHEGLOFF, 2000a, p. 17). Desse modo, observa-se um ajuste da produção "competitiva" para produção solo na fase de pósresolução da sobreposição. 
Apresentado o conjunto de recursos para o gerenciamento de sobreposições e os lugares em que podem ser mobilizados, cabe, então, compreender a lógica interacional do dispositivo para que tais recursos, em tais lugares, constituam "jogos" de uma espécie que pode ser descrita em uma topografia sequencial.

\section{3 "Lógica" interacional}

Schegloff (2000a, p. 19-22) sustenta que, quando se veem produzindo falas sobrepostas, os participantes da fala-em-interação atentam para um nível ainda mais detido do que aquele que normalmente opera no restante da sistemática para a tomada de turnos. Haveria, pois, uma orientação não somente para a forma como o turno é construído em relação ao turno anterior, ou em relação às unidades sintáticas que permitem a projeção de completude dos turnos, mas também para as batidas rítmicas, basicamente a marcação silábica da fala. Na operação do dispositivo para o gerenciamento de sobreposição na tomada de turnos para a conversa (e outros sistemas de trocas de fala com tomada de turnos gerenciada localmente), essa característica especial configura uma lógica interacional particular para o dispositivo. Desse modo, em relação à sobreposição, os participantes não se orientam somente para o que está sendo feito turno a turno, "falante corrente/próximo falante", e sim para o nível da batida. "A topografia da organização sequencial e interacional

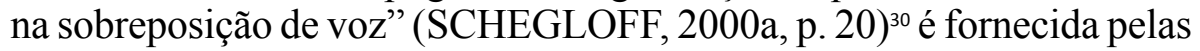
sucessivas batidas que a compõem. Podemos observar essa orientação no dado de sobreposição problemática analisado anteriormente.

Excerto (10) (detalhe do excerto (1)/(6)/(9)): Lógica interacional

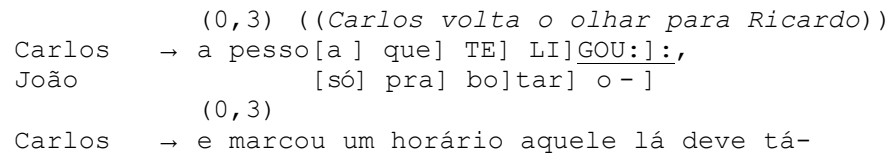

Após duas batidas de fala simultâneas, linhas 2-3, a fala de Carlos adquire um caráter de competitividade, pelo empreendimento de práticas como aumento de volume e prolongamento de sons. Após três batidas, em

30 "The topography of sequential and interactive organization in overlapping talk." 
que Carlos apresenta perturbações e contratempos em sua fala, João para de falar. Carlos também para de falar por um breve momento e continua sua fala do ponto onde parou, agora em produção solo.

A lógica interacional batida-a-batida se torna crucialmente operante no dispositivo para a resolução de fala sobreposta quando os participantes, ao se ouvirem em produção de fala simultânea durante a extensão de uma batida rítmica, não desistem de continuar e tampouco ouvem o interlocutor desistir. Observamos, como Schegloff (2000a, p. 22), que, "das sobreposições que sobrevivem à primeira batida, uma grande quantidade é cessada até uma batida após um dos falantes acirrar a fala para produção competitiva", ${ }^{31}$ conforme pode ser visto no excerto (10) (linhas 2-3). Ou seja, "a vasta maioria das sobreposições se resume a um só falante ao cabo da terceira batida" (SCHEGLOFF, 2000a, p. 24). ${ }^{32}$ De fato, no corpus cuja análise relatamos aqui, são poucas as ocorrências que exibem fala sobreposta além disso. A raridade desse tipo de sobreposição extensa em si manifesta a lógica interacional e a eficiência do dispositivo de resolução de sobreposição. Analisaremos, em seguida, uma ocorrência de sobreposição prolongada, que exige um exame mais detido pela particularidade de persistir por várias batidas.

\section{0 dispositivo para o gerenciamento de fala sobreposta em uma ocorrência de sobreposição de vozes prolongada na conversa coti- diana em português brasileiro}

O excerto que voltamos a examinar abaixo já foi apresentado como ocorrência de sobreposição de vozes problemática que ilustra o acionamento do dispositivo em posição de pré-resolução no excerto (8). Voltamos a esse dado outra vez por ele ter uma particularidade: a sobreposição persiste por seis batidas. Trata-se de um dado de interação face a face em que as três amigas, Camila, Gabi e Sabrina, estão conversando sobre o convite para a festa de casamento do irmão de Gabi. Nesse momento, as amigas, em enquadre de brincadeira, estão encenando o que Camila diria no momento da cerimônia de casamento diante da pergunta "Alguém tem alguma coisa contra esse casamento?", pois a

31 "Of the overlaps that survive the first beat, a great many are stopped within one beat after one of the speakers upgrades the talk to competitive production."

32 " [...] the vast majority of overlaps are resolved to a single speaker by the third beat." 
brincadeira consistiria na possibilidade de Camila se casar com o irmão da amiga. A sobreposição ocorre justamente quando Gabi e Camila tomam o turno para fazer a encenação de qual seria a resposta para a pergunta.

Excerto (11) (transcrição detalhada do excerto (8)): Sobreposição de vozes prolongada

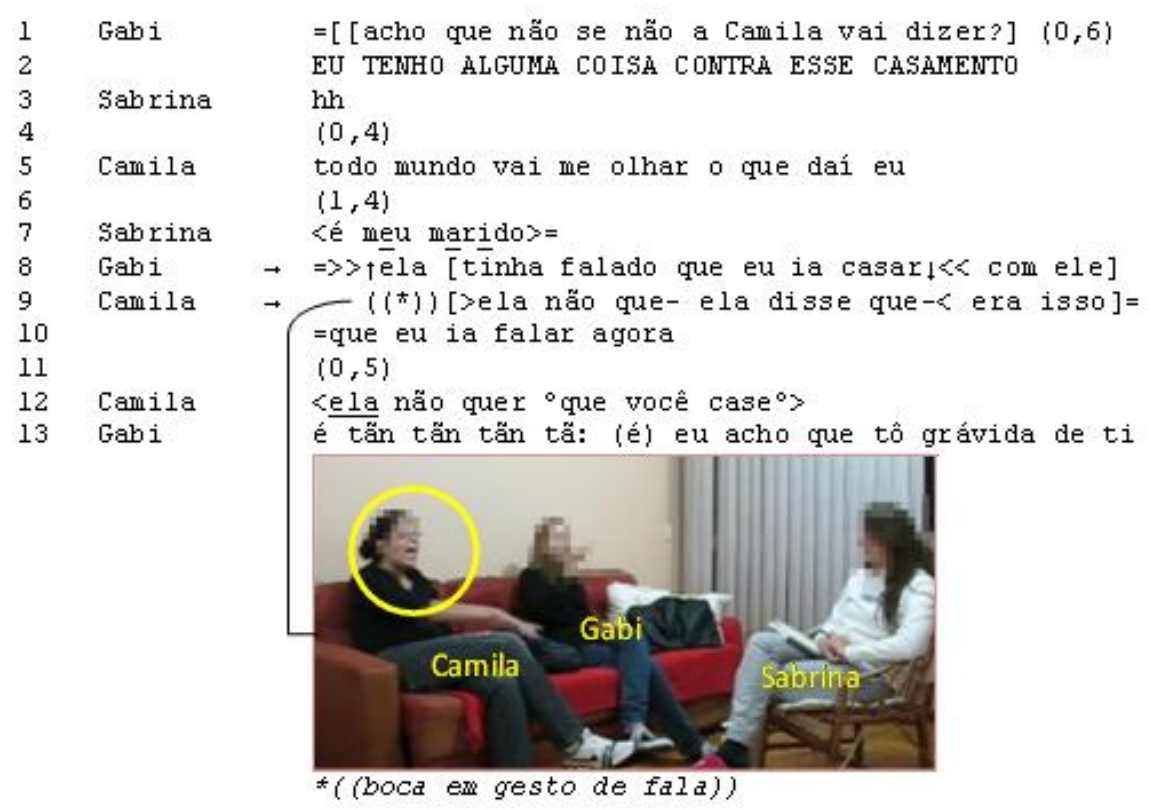

Nesses quadros parados, podemos primeiramente observar Camila e Gabi em sobreposição, linhas 8-9, ambas apresentando diversas perturbações em suas falas. Gabi, antes do começo efetivo da sobreposição de vozes, fala em um tom mais agudo e de maneira acelerada, possivelmente por projetar que Camila está por iniciar um turno (marcamos com um asterisco na transcrição o momento em que Camila abre a boca para falar, o que ocorre no momento em que Gabi inicia seu turno). Já Camila apresenta aceleração e cortes da fala durante a sobreposição. Em microanálise, identificamos as batidas de fala sobreposta na fala das participantes, que por vezes não se resumem a sílabas de palavras. 
Excerto (12) (detalhe do excerto (11)): Sobreposição de vozes prolongada

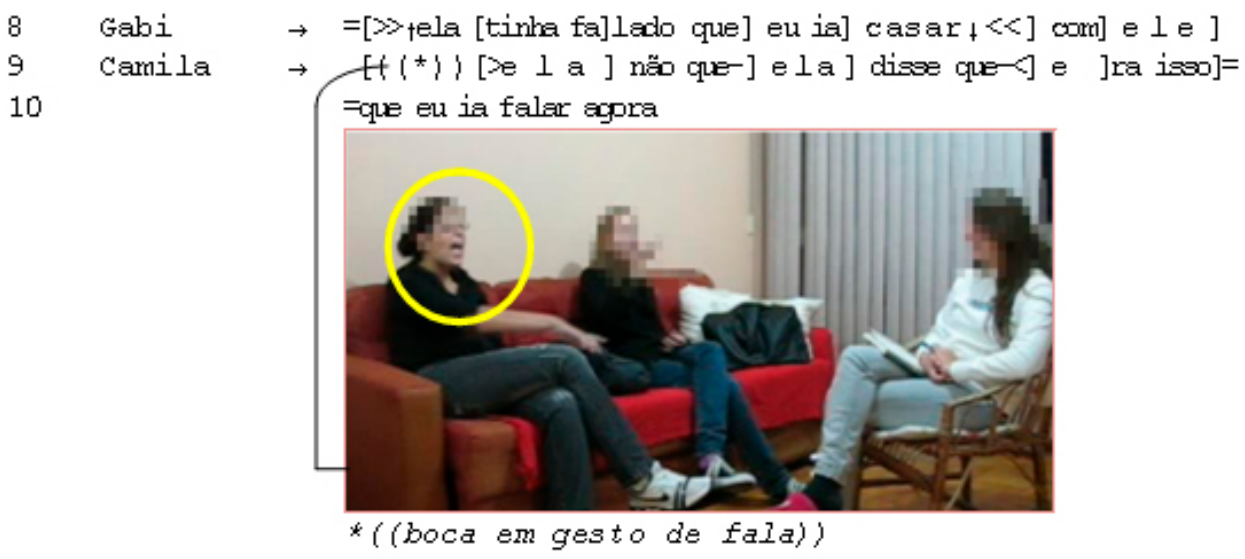

Ao observar as batidas de fala simultânea e os lugares/fases da sobreposição em que diferentes recursos estão sendo mobilizados, podemos ver de que maneira os participantes estão gerenciando a sobreposição. Da mesma maneira que analisamos o excerto (6), podemos ver na aceleração de Gabi, em uma posição de pré-inicio, uma tentativa de "não deixar espaço em que outro participante pudesse começar" (SCHEGLOFF, 2000a, p. 16). Gabi mantém a aceleração por toda sua fala, "brigando" pelo turno. Já Camila parece estar em busca da resolução da sobreposição. Isso fica claro pelos recursos que empreende: duas vezes corta sua fala, tentando manter o seu turno até Gabi terminar. Como foi analisado anteriormente, Gabi e Camila se aproximam da completude possível das unidades de construção de turno que estão produzindo em sobreposição. Cada uma pode escutar que a outra está chegando a uma completude possível. Camila mobiliza recursos pouco antes da completude possível do turno de Gabi, em uma posição de pré-resolução da sobreposição, antes que a sobreposição efetivamente termine.

Além de analisar os recursos e em que lugares eles estão sendo mobilizados, verificamos que o comportamento corporal dos participantes revela suas orientações para o gerenciamento da sobreposição. Primeiro, observemos o direcionamento de olhar: 
Excerto (13) (detalhe do excerto (11): Sobreposição de vozes prolongada

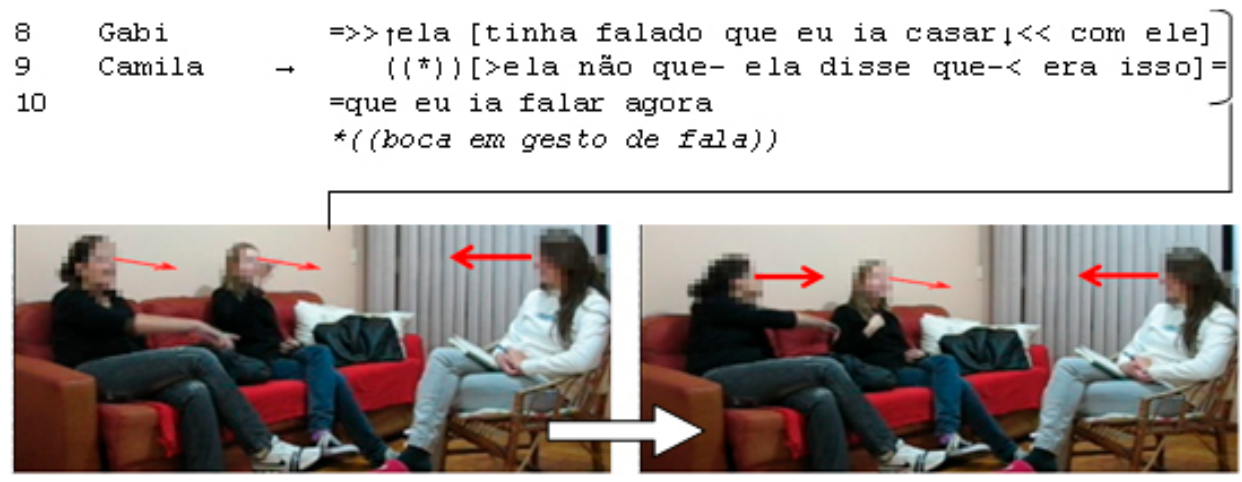

Nesses dois quadros parados podemos observar primeiramente Camila e Gabi olhando para frente, quando começam a se sobrepor. Já em "ela disse que-", Camila direciona o torso e o olhar para Gabi, orientando-se para a fala da coparticipante, enquanto Gabi, persistindo em sobreposição, continua a olhar para frente na mesma postura. Sabrina parece estar olhando para frente, mas não é possível ver para quem exatamente ela está olhando.

De modo semelhante, os gestos também indicam a orientação dos participantes para a sobreposição, acompanhando o direcionamento de olhar e os recursos empreendidos na fala para produção do turno. Vemos que o gesto de Camila começa apontado para frente, mas se volta para Gabi, sendo também um possível indicador de orientação para o turno da amiga. Os gestos de Gabi estão intimamente ligados ao que ela está encenando. 
Excerto (14) (detalhe do excerto (11)): Sobreposição de vozes prolongada

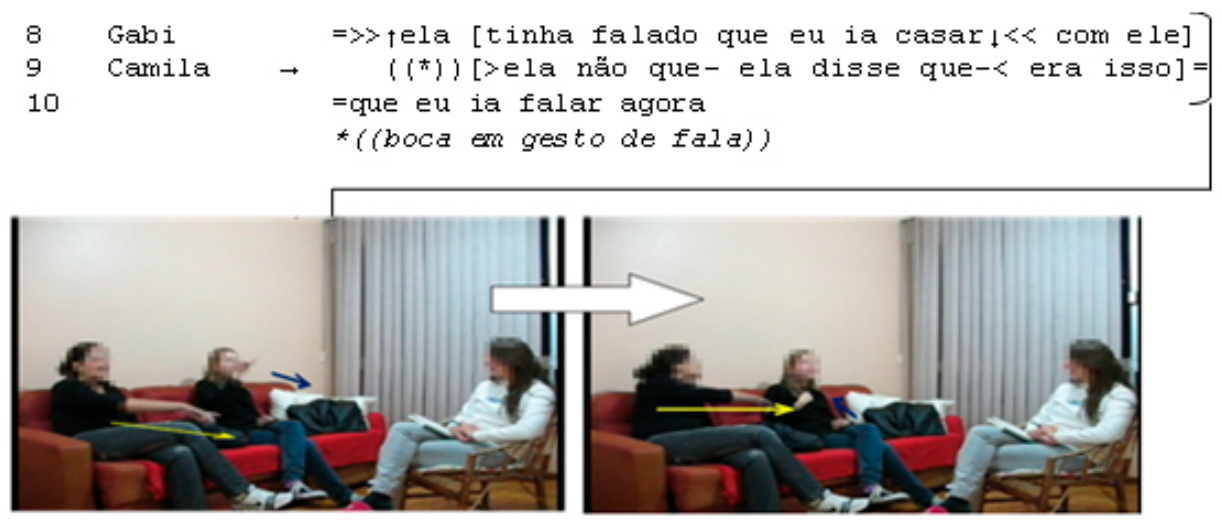

De fato, sobreposições estendidas do tipo que acabamos de examinar não são, portanto, nada comuns. Esse é um caso em que, como observa Schegloff (2000a, p. 27), mais do que um esbarrão na tomada de turnos, as participantes parecem ter interesses especiais. $\mathrm{O}$ que podemos observar nesse dado é que as duas participantes parecem estar comprometidas a dizer o que querem dizer nesse exato momento, nessa posição de turno, e não mais tarde. Ambas consideram oportuna sua encenação de resposta a "Alguém tem alguma coisa contra esse casamento?", já que as duas poderiam responder a essa pergunta, devido aos papéis que desempenham na situação imaginária. Assim, as duas mobilizam recursos para gerenciar a sobreposição, a fim de levar a cabo suas ações.

Entender as razões para a ocorrência de uma sobreposição prolongada pode levar ao diagnóstico sobre "os projetos interacionais que alimentam essa sobreposição" (SCHEGLOFF, 2000a, p. 29). ${ }^{33}$ Por fim, o interesse por essas ocorrências surge mais pela dramaticidade que pode estar atrelada a elas do que por sua frequência. Assim, pela raridade de sobreposições problemáticas, "não é verdade que "falar de sobreposição é falar de luta pela palavra"” (SCHEGLOFF, 2000a,

33 "[...] the interactional projects that fuel it $[\ldots] "$ ". 
p. 29). ${ }^{34}$ Isso é importante para que tenhamos em vista que, nessas ocasiões interacionais singulares, há um dispositivo para gerenciamento e resolução de sobreposições. Mesmo aqui, portanto, não se trata de usurpação dos direitos interacionais de outrem, de "ruptura, caos ou desordem interacional", nem de que algum falante está "sendo desatento ou desleixado" (DREW, 2009, p. 72). ${ }^{35}$ Trata-se do funcionamento regular da organização da fala-em-interação.

\section{Considerações finais}

Na investigação relatada aqui, encontramos nos dados de conversa entre falantes de português brasileiro ocorrências de sobreposições tal como foi previsto a partir da descrição feita por Schegloff (2000a) para dados de conversa entre falantes de inglês (norte-americano). Se pudemos, nessa primeira incursão, encontrar boa parte dos fenômenos de fala sobreposta, cabe dizer que elas envolvem considerável complexidade. Acreditamos ter oferecido uma descrição em que ilustramos os principais aspectos do fenômeno, apresentando análises mais acessíveis ao leitor brasileiro do que as do artigo original de Schegloff(2000a). Contudo, ainda que baseada em nosso melhor entendimento da descrição e dos próprios fenômenos, nossa análise ainda é exploratória e pode vir a ser aprimorada.

Um aspecto saliente quanto a isso diz respeito ao fato de nossos dados envolverem três participantes. Schegloff (1995, p. 39; 2000a, p. 10) observa que "é certamente possível que dois participantes vão lidar diferentemente com as falas sobrepostas que dirigem um ao outro, dependendo se há outros coparticipantes ratificados, ou se os dois são os únicos presentes". ${ }^{36}$ Com efeito, o autor aponta ainda três configurações para a ocorrência de sobreposições em conversas com mais de dois participantes:

\footnotetext{
34 "It is not the case that 'who says overlap says fight for the floor'."

35 " [...] interactional breakdown, chaos or disorder [...] is being inattentive or sloppy." 36 "It is surely possible that two participants will deal with their overlapping talk to each other differently, depending on whether there are other ratified co-participants, or whether these two are the only ones present."
} 

(i) $\begin{aligned} & \mathrm{A} \rightarrow \mathrm{B} \\ & \downarrow \\ & \mathrm{C}\end{aligned}$
(ii) $\mathrm{A} \rightarrow \mathrm{B}$
(iii) $\mathrm{A} \leftrightarrow \mathrm{B}$
C
$\mathrm{C}$

Figura 1 - Configurações para ocorrência de sobreposições de vozes

Fonte: Schegloff (1995, p. 39; 2000a, p. 10).

Na primeira configuração, vemos dois participantes, (A) e (B), em sobreposição: (A) endereça sua fala para (B), e (B) para (C). Já na segunda, vemos os participantes $(A)$ e $(C)$ em sobreposição, pois ambos direcionam sua fala para o participante (B). Na terceira configuração, um participante (A) endereça sua fala a um participante (B), e vice-versa, sem um terceiro participante envolvido na alocação de turnos. Segundo Schegloff (2000a), para compreender o fenômeno de sobreposição de vozes e verificar como ela é resolvida, deveríamos enfocar primeiramente essa terceira configuração, o caso mais geral de sobreposição, pois ela teria o número mínimo de participantes necessários para interação, que é dois (além de esse ser o número de participantes que geralmente estão falando ao mesmo tempo). ${ }^{37}$

Já sobreposições nas configurações (i) e (ii), por envolverem três participantes, podem ter suas trajetórias determinadas como problemáticas ou não em relação à ratificação de interlocutores endereçados. Em Schegloff (2000a), encontramos análises de gerenciamento de sobreposições problemáticas em ocorrências de configuração (i) e (ii) em que isso não entra em questão. Não obstante, em estudo anterior (STEIN; GARCEZ, 2011), encontramos casos em que a sobreposição nessas configurações não requer gerenciamento, pois a fala sobreposta não é problemática, justamente pela ratificação de um interlocutor endereçado. Analisamos ocorrências de sobreposições em conversas entre cinco participantes e atestamos que, nesses casos, o direcionamento de olhar é determinante para a resolução da sobreposição, pois os participantes estabelecem qual turno ou ação sobreposto(a) será ratificado(a) pela atenção de um mesmo interlocutor endereçado, tornando desnecessário o empreendimento de práticas para o gerenciamento da fala simultânea.

\footnotetext{
${ }^{37}$ Schegloff (2000a) sustenta que, em relação ao gerenciamento de sobreposição, os participantes somente se orientam a um outro único falante no trabalho de resolver a sobreposição.
} 
Assim, de fato, casos de sobreposição nas configurações (i) e (ii) não entram em questão quando se está falando em gerenciar sobreposições. No entanto, nos dados apresentados aqui, encontramos sobreposições problemáticas de fato mesmo nessas configurações e que se mostraram adequados para observação dos principais aspectos do fenômeno conforme foram apresentados por Schegloff (2000a, p. 10) como "as práticas de conduta pelas quais os falantes em sobreposição lidam com as suas falas simultâneas são formadas em primeiro lugar para lidar com fala entre dois, um para o outro". ${ }^{38}$ Dados os nossos objetivos e o propósito mais amplo de desenvolver um conhecimento firme da descrição seminal sobre o dispositivo de gerenciamento de sobreposições com vistas a construir bases sólidas para sua observação também em fala-em-interação com múltiplos participantes (como a fala-em-interação de sala de aula), pareceu-nos adequado o exame de conversas entre três participantes, ${ }^{39} \mathrm{em}$ configurações variáveis e, muitas vezes, de difícil discriminação. Não resta dúvida, entretanto, que cabem estudos adicionais com apenas dois participantes, conversando exclusivamente entre si, para confirmação ou refutação do que apresentamos aqui.

Confiamos, portanto, que o trabalho que empreendemos pode servir como alicerce para estudos futuros, tanto em conversa cotidiana como em cenários institucionais de fala-em-interação, para que pesquisadores da interação social promovam análises rigorosas e precisas do gerenciamento de fala sobreposta e da organização da falaem-interação.

\footnotetext{
38 “ "...] practices of conduct by which overlapping speakers deal with their simultaneous talk are formed in the first place to deal with talk by two, to each other."

${ }^{39}$ Note-se que o próprio Schegloff (2000a) se vale de dados com três participantes para análise, por exemplo, de sobreposição prolongada interacionalmente delicada (p. 25-27) e também para descrição das fases da sobreposição em que se observa mobilização de diferentes práticas de gerenciamento (p. 16-17), nesse caso em dado que ele mesmo atesta como alternante entre as configurações (i) e (ii) (ver p. 9-11).
} 


\section{Referências}

ATKINSON, J. M.; HERITAGE, J. (Org.). Structures of Social Action. Cambridge (MA): Cambridge University Press, 1984.

BILMES, J. The Concept of Preference in Conversation Analysis. Language in Society, v. 17, p. 161-181, 1988.

CLARK, H. O uso da linguagem. Cadernos de Tradução, Porto Alegre, v. 9, p. 49-71, jan.-mar. 2000.

COATES, J. One-at-a-time: The Organization of Men's Talk. In: JOHNSON, S.; MEINHOF, U. H. (Org.). Language and Masculinity. Oxford (UK): Blackwell, 1997. p. 107-129.

COUPER-KUHLEN, E.; SELTING, M. (Org.). Prosody in Conversation: Interactional Studies. Cambridge (UK)/New York: Cambridge University Press, 1996.

DREW. P. "Quit Talking While I'm Interrupting": A Comparison between Positions of Overlap Onset in Conversation. In: HAAKANA, M.; LAAKSO, M.; LINDSTRÖM, J. (Org.). Talk in Interaction: Comparative Dimensions. Helsinque: Finnish Literature Society, 2009. p. 70-93.

GARCEZ, P. M. Formas institucionais de fala-em-interação e conversa cotidiana: elementos para a distinção a partir da atividade de argumentar. Revista paLavra, Rio de Janeiro, v. 8, p. 54-73, 2002.

GARCEZ, P. M. A perspectiva da Análise da Conversa Etnometodológica sobre o uso da linguagem em interação social. In: LODER, L. L.; JUNG, N. M. (Org.). Fala-em-interação social: introdução à Análise da Conversa Etnometodológica. Campinas: Mercado de Letras, 2008. p. 17-38.

GARCEZ, P. M.; LODER, L. L. Reparo iniciado e levado a cabo pelo outro na conversa cotidiana em português do Brasil. DELTA: Documentação de Estudos em Lingüística Teórica e Aplicada, São Paulo, v. 21, n. 2, p. 279-312, jul.-dez. 2005.

GARDNER, R.; MUSHIN, I. Post-start-up Overlap and Disattentiveness in Talk in a Garrwa Community. Australian Review of Applied Linguistics, v. 30, p. 1-14, 2007.

JEFFERSON, G. A Case of Precision Timing in Ordinary Conversation: Overlapped Tag-positioned Address Terms in Closing Sequences. Semiotica, v. 9, p. 47-96, 1973. 
192 Revista de Estudos da Linguagem, Belo Horizonte, v.23, n.1, p. 159-194, 2015

JEFFERSON, G. On a Failed Hypothesis: "Conjunctionals" as Overlapvulnerable. Tilburg Papers in Language and Literature, v. 28, p. 1-33, 1983.

JEFFERSON, G. Notes on Some Orderlinesses of Overlap Onset. In: D'URSO, V.; LEONARDI, P. (Org.). Discourse Analysis and Natural Rhetorics. Pádua: CLEUP, 1984. p. 11-38.

JEFFERSON, G. Notes on "Latency" in Overlap Onset. Human Studies, v. 9 , p. $153-83,1986$.

LODER, L. L.; JUNG, N. M. (Org.). Fala-em-interação social: introdução à Análise da Conversa Etnometodológica. Campinas: Mercado de Letras, 2008.

LODER, L. L.; SALIMEN, P.; MÜLLER, M. Noções fundamentais: sequencialidade, adjacência e preferência. In: LODER, L. L.; JUNG, N. M. (Org.). Fala-em-interação social: introdução à Análise da Conversa Etnometodológica. Campinas: Mercado de Letras, 2008. p. 95-126.

LODER, L. O modelo Jefferson de transcrição: convenções e debates. In: LODER, L. L.; JUNG, N. M. (Org.). Fala-em-interação social: introdução à Análise da Conversa Etnometodológica. Campinas: Mercado de Letras, 2008. p. 127-160.

MAREGA, L. M. P.; JUNG, N. M. A sobreposição de falas na conversa cotidiana: disputa pela palavra? Veredas, Juiz de Fora, v. 15, p. 321-337, 2011.

MCCLEARY, L. E.; LEITE, T. A. Turn-taking in Brazilian Sign Language: Evidence from Overlap. Journal of Interactional Research in Communication Disorders, v. 4, p. 123-154, 2013.

OCHS, E.; SCHEGLOFF, E. A.; THOMPSON, S. (Org.). Interaction and Grammar. Cambridge (UK): Cambridge University Press, 1996.

POMERANTZ, A. Agreeing and Disagreeing with Assessments: Some Features of Preferred/Dispreferred Turn Shapes. In: ATKINSON, J. M.; HERITAGE J. (Org.). Structures of Social Action: Studies in Conversation Analysis. Cambridge (UK): Cambridge University Press, 1984. p. 57-101.

POMERANTZ, A. Preference Organization Revisited: Displaying Speaker's Stance toward Performing an Action. Trabalho submetido à Associação Norte-Americana de Sociologia, 2008. Disponível em: $<$ http:// www.allacademic.com//meta/p_mla_apa_research_citation/2/3/7/4/6/ pages237466/p237466-1.php>. Ācesso em: 17 fev. $\overline{2014}$. 
SACKS, H. Lectures on Conversation. Oxford (UK)/Cambridge (UK): Blackwell, 1992. v. 1-2.

SACKS, H.; SCHEGLOFF, E. A.; JEFFERSON, G. Sistemática elementar para a organização da tomada de turnos para a conversa. Veredas, Juiz de Fora, v. 7, p. 9-73, 2003. [Tradução de SACKS, H.; SCHEGLOFF, E. A.; JEFFERSON, G. A Simplest Systematic for the Organization of Turntaking for Conversation. Language, v. 50, p. 696-735, 1974.]

SCHEGLOFF, E. A. Between Micro and Macro: Contexts and Other Connections. In: ALEXANDER, J. C.; GIESEN, B.; MÜNCH, R.; SMELSER, N. J. (Org.). The Micro-macro Link. Berkeley: University of California Press, 1987. p. 207-234.

SCHEGLOFF, E. Parties and Talking Together: Two Ways Numbers are Significant. In: TEN HAVE P.; PSATHAS, G. (Org.). Situated Order. Washington: University Press of America, 1995. p. 31-42.

SCHEGLOFF, E. Overlapping Talk and the Organization of Turn-taking for Conversation. Language in Society, v. 29, p. 1-63, 2000a.

SCHEGLOFF, E. When 'Others' Initiate Repair. Applied Linguistics, v. 21, p. 205-243, 2000b.

SCHEGLOFF, E. On Granularity. Annual Review of Sociology, v. 26, p. 715-720, 2000c.

SCHEGLOFF, E. Accounts of Conduct in Interaction: Interruption, Overlap, and Turn-taking. In: TURNER, J. H. (Org.). Handbook of Sociological Theory. New York: Kluwer Academic/Plenum, 2002. p. 287-321.

SCHEGLOFF, E. A Tutorial on Membership Categorization. Journal of Pragmatics, v. 39, p. 462-482, 2007 a.

SCHEGLOFF, E. A.; JEFFERSON, G.; SACKS, H. The Preference for Self-correction in the Organization of Repair in Conversation. Language, v. 53, p. 361-383, 1977.

SIDNELL, J. Conversational Turn-taking in a Caribbean English Creole. Journal of Pragmatics, v. 33, p. 1263-1290, 2001.

STEIN, F.; GARCEZ, P. M. Direcionamento de olhar como prática organizacional da tomada de turnos e o gerenciamento de fala sobreposta em conversa cotidiana entre múltiplos participantes. In: SALÃO DE 
INICIAÇÃO CIENTÍFICA, 23., 3-7 out. 2011, Universidade Federal do Rio Grande do Sul, Porto Alegre. Disponível em: <http://hdl.handle. net/10183/48446> (resumo e pôster). Acesso em: 14 fev. 2014.

WEST, C. When the Doctor is a 'Lady': Power, Status and Gender in Physician-patient Encounters. In: COATES, J. (Org.). Language and Gender: A Reader. Oxford (UK): Blackwell, 1998. p. 396-412.

WEST, C.; ZIMMERMAN, D. H. Pequenos insultos: estudo sobre interrupções em conversas sobre pessoas desconhecidas e de diferentes sexos. In: OSTERMANN, A. C.; FONTANA, B. (Org.). Linguagem, gênero, sexualidade: clássicos traduzidos. Tradução de Ana Cristina Ostermann e Beatriz Fontana. São Paulo: Parábola, 2010 [1983]. p. 49-66. WONG, J. Delayed Next-turn Repair-initiation in Native/Non-native Speaker English Conversation. Applied Linguistics, v. 21, p. 244-267, 2000.

ZIMMERMAN, D. H. Horizontal and Vertical Comparative Research in Language and Social Interaction. Research on Language and Social Interaction, v. 32, p. 195-203, 1999. 